\title{
PHOTOSYNTHESIS, STOMATAL CONDUCTANCE, ENDOGENOUS HORMONES AND ORGANIC ACID SYNERGISTIC REGULATION IN LEAVES OF RICE (ORYZA SATIVA L.) UNDER ELEVATED $\mathrm{CO}_{2}$
}

\author{
QI, X. F. - WANG, X. H. - WANG, Q. - LI, M. - MA, L. J. - LI, Y. Y. - LI, X. M." - WANG, L. L." \\ College of Life Science, Shenyang Normal University \\ No. 253 Huanghe North Street, Shenyang, Liaoning 110034, China \\ ${ }^{*}$ Corresponding authors \\ e-mail:wangqi5387402006@163.com,lxmls132@163.com
}

(Received $9^{\text {th }}$ Apr 2021; accepted $8^{\text {th }}$ Jul 2021)

\begin{abstract}
To study the photosynthesis, stomatal conductance, endogenous hormones and organic acid regulation in leaves of rice seedlings under elevated $\mathrm{CO}_{2}$, rice were exposed to different $\mathrm{CO}_{2}$ concentrations ( $400 \pm 20 \mu \mathrm{mol} \mathrm{mol}^{-1}$, AA; $600 \pm 20 \mu \mathrm{mol} \mathrm{mol}^{-1}$, LEC; $800 \pm 20 \mu \mathrm{mol} \mathrm{mol}^{-1}$, HEC) for 7 days. The results showed that: The elevated $\mathrm{CO}_{2}$ increased IAA (Indole-3-acetic acid, IAA), ZT (Zeatin, ZT) and $\mathrm{GA}_{3}$ (Gibberellins $\mathrm{A}_{3}, \mathrm{GA}_{3}$ ) contents significantly $(\mathrm{p}<0.05)$, which regulated the increasing $\mathrm{P}_{\mathrm{n}}$ (Light-saturated net photosynthesis rate, $\mathrm{P}_{\mathrm{n}}$ ) and $\mathrm{Fv} / \mathrm{Fm}$ (Maximum quantum yield of PSII photochemistry, Fv/Fm); Gs (Stomatal conductance, Gs) and $\operatorname{Tr}$ (Transpiration rate, $\operatorname{Tr}$ ) were all decreased significantly $(\mathrm{p}<0.05)$, while ABA (Abscisic acid, ABA) content also decreased, but JA (Jasmonic acid, JA) content increased significantly $(p<0.05)$ under EC. Perhaps, the movements of stoma were connected with JA in some degree, but not $\mathrm{ABA} ; \mathrm{IAA} / \mathrm{ABA}, \mathrm{GA}_{3} / \mathrm{ABA}$ and $\mathrm{ZT} / \mathrm{ABA}$ were all increased under $\mathrm{EC}$, indicating the promoting effects of photosynthesis. JA/GA 3 decreased under LEC, but increased under HEC, which regulated the elevated Pn under LEC, and severe closure of stomata under HEC. The contents of oxalic acid, tartaric acid, acetic acid, malic acid, lactic acid, fumaric acid and succinic acid significantly decreased $(\mathrm{P}<0.05)$ in leaves, but contents of citric acid showed no significant difference with AA under HEC, indicating that the TCA cycle rate slowed down.
\end{abstract}

Keywords: elevated $\mathrm{CO}_{2}$, photosynthesis, Gs, $A B A$, JA, malic acid, fumaric acid

\section{Introduction}

The accumulating $\mathrm{CO}_{2}$ level has increased over two-fold since the industrial revolution (Guo et al., 2017). This resulted mainly from emissions of fossil fuel burning and net land use change (IPCC, 2013). As the carbon donor of plant photosynthesis, the increase of atmospheric $\mathrm{CO}_{2}$ concentration is beneficial to the photosynthesis of plants, but decreases stomatal conductance and transpiration rate of leaves (Wang et al., 2019). Stomata play a major role in controlling $\mathrm{CO}_{2}$ uptake for photosynthesis and water release by transpiration (Tanaka et al., 2013). Endogenous hormones of plants are micro-signal molecules involved in their metabolism. The guard cells are sensitive to environmental factors such as light, temperature, water and $\mathrm{CO}_{2}$, which in turn means that they transmit information through changes in plant endogenous hormone levels, such as ABA which is always believed to be an important hormone that decreases the stomatal aperture (McAdam et al., 2011). Study have shown that in addition to ABA receptors, there are also IAA receptors in the guard cells, and the effect of high auxin concentrations on stomatal closure may be related to the regulation of anion channels on membrane of guard cells (Marten, 1991). In recent years, as new endogenous hormones, JAs and SA has received extensive attention. JA can promote stomatal closure and prevent stomatal opening in orchids and other plants (Gehring et al., 1997). JA and its 
precursor linolenic acid (linolenic acid, LA) can reduce the transpiration rate of tomato (Herde et al., 1997). SA (Salicylic acid, SA) also can decrease the stomatal aperture under certain conditions (Manthe et al., 1992). Plant responses usually regulated by the balance of different hormones, not just the concentration of a single hormone. Synergistic or antagonistic interactions among the different hormone groups add to the complexity of the hormonal system in higher plants (Wilhelm, 2015). Recently, physiologists of plant have provided lots of examples of links between activities of various hormones, that is called "crosstalk", such as JA is involved in crosstalk with SA, auxin, GA and ABA. Common organic acids include citric acid, oxalic acid, acetic acid, fumaric acid, lactic acid, malic acid, succinic acid, tartaric acid, etc., which can regulate various physiological metabolic processes of plants (Dakora and Phillips, 2002). Most of the organic acids come from the tricarboxylic acid cycle (TCA), including some intermediates of glyoxylic acid cycle and can reduce the toxicity of plants to a certain extent (Javed et al., 2017; Fu et al., 2018). At present, most studies focus on organic acids secreted by roots, there are few studies on the changes of organic acids contents in plants and under elevated $\mathrm{CO}_{2}$ environment, so the objective of this study was to measure stomatal conductance, changes of endogenous hormones (including $\mathrm{ABA}, \mathrm{GA}_{3}$, IAA, JA, SA and ZT) contents and organic acids (including oxalate, tartarate, malate, lactate, acetate, citate, succinate and frumarate) contents of rice seedlings (Oryza sativa L.) leaves, so as to know the physiological mechanism response of plants to changed atmosphere environment and provide theoretical basis for the plant growth and crop cultivation in the future.

\section{Materials and Methods}

\section{Plant materials and treatments}

The uniform and healthy rice seeds (Beijing 2, which has been widely planted in Liaoning province, China) were sterilized, rinsed, and germinated in the dark. The germinating seeds were transferred to beakers containing Hoagland solution (Hoagland and Arnon, 1950). Seedlings were maintained in an artificial climate chamber (14/10 h light/dark period, $28 / 22^{\circ} \mathrm{C}$ day/night, $80 \%$ relative air humidity and $800 \mu \mathrm{mol} \mathrm{m} \mathrm{s}^{-1}$ photosynthetic photon flux density) until to the two-leaves-stage. Then the rice seedlings were divided into three groups: (1) AA, rice seedlings cultured under $\mathrm{CO}_{2}$ concentration of $400 \pm 20 \mu \mathrm{mol} \mathrm{mol}{ }^{-1}$. (2) LEC, rice seedlings cultured under $\mathrm{CO}_{2}$ concentration of $600 \pm 20 \mu \mathrm{mol} \mathrm{mol}{ }^{-1}$. (3) $\mathrm{HEC}$, rice seedlings cultured under $\mathrm{CO}_{2}$ concentration of $800 \pm 20 \mu \mathrm{mol} \mathrm{mol}{ }^{-1}$. All the rice seedlings were cultured for 7 days, then were measured for gas exchange parameters, Chlorophyll a fluorescence parameter $(\mathrm{Fv} / \mathrm{Fm})$, hormones contents and organic acids contents. Three repeats were selected randomly in each pot ( 3 pots/treatment, a total of 9 repeats/treatment).

\section{Growth parameters measurements}

Plant height and taproot length were measured using a scale. The sampling plant was divided into the aboveground part and the underground part from the stem base, and the fresh weight was weighed. The plants that have been weighed fresh were placed in an oven at $120^{\circ} \mathrm{C}$ for 6 hours, and then placed at $80^{\circ} \mathrm{C}$ for 2 hours, and dried until the weight does not change. The dry weight was weighed. Each treatment group was repeated for 3 groups, and 10 plants were selected from each group for average value. 


\section{Gas exchange parameters measurements}

Light-saturated net photosynthesis rate $(\mathrm{Pn})$, transpiration rate $(\mathrm{Tr})$ and stomatal conductance (Gs) were recorded under saturated light between 09:00 and 11:00 by a portable photosynthesis system (LI-6400, Li-Cor Inc., Lincoln NE, USA).

\section{Chlorophyll a fluorescence measurements}

Chlorophyll a fluorescence parameter (Fv/Fm, maximum quantum yield of PSII photochemistry) was measured after 20-minute dark-adaption of leaves, using a portable fluorometer (Handy-PEA, Hansatech, England).

\section{Extraction and analysis of hormones}

Rice seedling leaves were homogenized by methanol and cross-chain polyvinyl pyrrolidone (PVPP) in an ice tray. The homogenate was immersed and extract in a refrigerator at $4^{\circ} \mathrm{C}$ for 12 hours, then centrifuged for supernatant. The residue was extracted for 3 times using the same method and the supernatant is merged. The supernatant was placed in a $4^{\circ} \mathrm{C}$ incubator (dark) to blow dry. The dry sample was dissolved with $100 \%$ methanol then centrifuged for supernatant. The supernatant was firstly filtered through $0.45 \mu \mathrm{m}$ nylon filters and secondly through $0.22 \mu \mathrm{m}$ nylon filters, then stored at $4^{\circ} \mathrm{C}$. Samples were analyzed using an Agilent 1200 HPLC equipped with a reverse phase $\mathrm{C} 18$ column $(250 \times 4.6 \mathrm{~mm})$.

The column was operated at $35^{\circ} \mathrm{C}$. Isocratic Elution was carried at a flow rate of $0.8 \mathrm{~mL} / \mathrm{min}$. The injection volume was $20 \mu \mathrm{L}$, with methanol/acetic acid/distilled water (45:0.8:54.2, v/v/v) as the mobile phase. Chromatograms were acquired at $254 \mathrm{~nm}$ with standards for ABA, ZT, SA, IAA and GA 3 (purchased from Sigma Aldrich).

The column was operated at $30^{\circ} \mathrm{C}$. Isocratic Elution was carried out at a flow rate of $0.3 \mathrm{~mL} / \mathrm{min}$. The injection volume was $20 \mu \mathrm{L}$, with methanol/formic acid/distilled water $(65: 0.035: 34.965, \mathrm{v} / \mathrm{v} / \mathrm{v})$ as the mobile phase. Chromatogram was acquired at $254 \mathrm{~nm}$ with standard for JA (purchased from Sigma Aldrich) (Jensen and Junttila, 1982; Hou et al., 2008).

\section{Extraction and analysis of organic acids}

$0.5 \mathrm{~g}$ of rice seedlings leaves were put into a mortar, and $3 \mathrm{ml}$ of distilled water was added to grind them to the homogenate at the same time, treated with ultrasonic for $30 \mathrm{~min}\left(25^{\circ} \mathrm{C}\right)$, then water bath for $15 \mathrm{~min}\left(75^{\circ} \mathrm{C}\right)$, centrifugally take the supernatant. Filtered supernatant in a disposable filter with an aperture of $0.45 \mu \mathrm{m}$, and then filtered it with an aperture of $0.22 \mu \mathrm{m}$, and stored it in a refrigerator with a temperature of $4^{\circ} \mathrm{C}$. Samples were analyzed using an Agilent1200 HPLC equipped with a reverse phase C18 column $(250 \times 4.6 \mathrm{~mm})$.

The column was operated at $35^{\circ} \mathrm{C}$. Isocratic Elution was carried at a flow rate of $0.8 \mathrm{~mL} / \mathrm{min}$. The injection volume was $20 \mu \mathrm{L}$, with $0.01 \mathrm{mM} \mathrm{H}_{2} \mathrm{SO}_{4} /$ methanol (96:4, $\mathrm{v} / \mathrm{v})$ as the mobile phase. Chromatograms were acquired at $210 \mathrm{~nm}$ with standards for oxalate, tartarate, malate, lactate, acetate, citate, succinate and frumarate (purchased from Sigma Aldrich) (Lodi and Rossin, 1995; Zhen et al., 2000). 


\section{Statistical analysis}

ANOVA was carried out to analyze all sets of data using SPSS 20.0 computer package and the Tukey test at 5\% probability Levels were used to compare the means. Sample variability is given as the standard deviation (S.D.) for presentation.

\section{Results}

\section{Effects of elevated $\mathrm{CO}_{2}$ on plant growth parameters}

The plant height and root length were significant $(\mathrm{p}<0.05)$ increased by $12.3 \%, 9.3 \%$ and $10.7 \%, 7.1 \%$, respectively under LEC and HEC compared with AA. The fresh weight of the aboveground part significant $(\mathrm{p}<0.05)$ increased by $10.9 \%$ and $12.1 \%$, and the fresh weight of the underground part significant $(\mathrm{p}<0.05)$ increased by $50.7 \%$ and 70.3\% under LEC and HEC, compared with AA. Compared with AA, the underground dry weight of was significant $(\mathrm{p}<0.05)$ increased by $57.6 \%$ and $80.4 \%$, and the dry weight of aboveground part was significant $(\mathrm{p}<0.05)$ increased by $19.1 \%$ and $27.4 \%$ under LEC and HEC (Fig. 1).

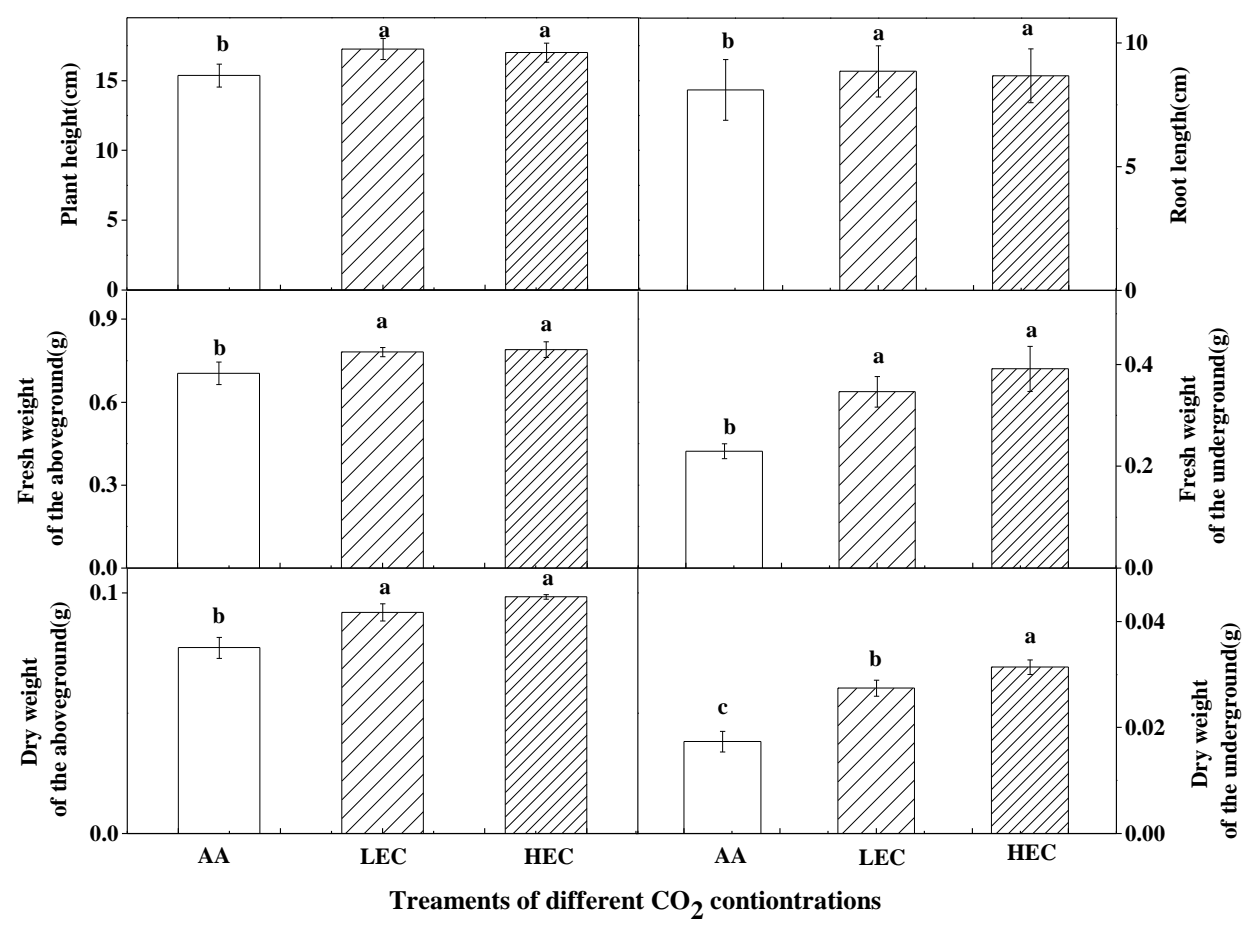

Figure 1. Effects of $\mathrm{CO}_{2}$ treatments on plant growth parameters of rice seedlings. The rice seedlings were cultured under different $\mathrm{CO}_{2}$ concentrations $\left(400 \pm 20 \mathrm{\mu mol} \mathrm{mol}^{-1}, \mathrm{AA} ; 600 \pm 20\right.$ $\mu \mathrm{mol} \mathrm{mol} l^{-1}, \mathrm{LEC} ; 800 \pm 20 \mathrm{\mu mol} \mathrm{mol}^{-1}, \mathrm{HEC}$ ). The bars indicated standard error. The significance differences were marked as abc at $P<0.05$ (Tukey test). The following figures are consistent with this figure. $(n=30)$

\section{Effects of elevated $\mathrm{CO}_{2}$ on Pn, Fv/Fm, gs and Tr}

$\mathrm{P}_{\mathrm{n}}$ was significantly $(\mathrm{p}<0.05)$ increased under LEC and HEC compared with AA. The maximum difference (about 19.1\%) was recorded under LEC; Fv/Fm was only 
significantly $(\mathrm{p}<0.05)$ increased under LEC, but not HEC compared with AA. LEC and HEC decreased Gs and Tr significantly $(\mathrm{p}<0.05)$ compared to the control, and Gs and $\mathrm{Tr}$ were lower under HEC than under LEC (Fig. 2).

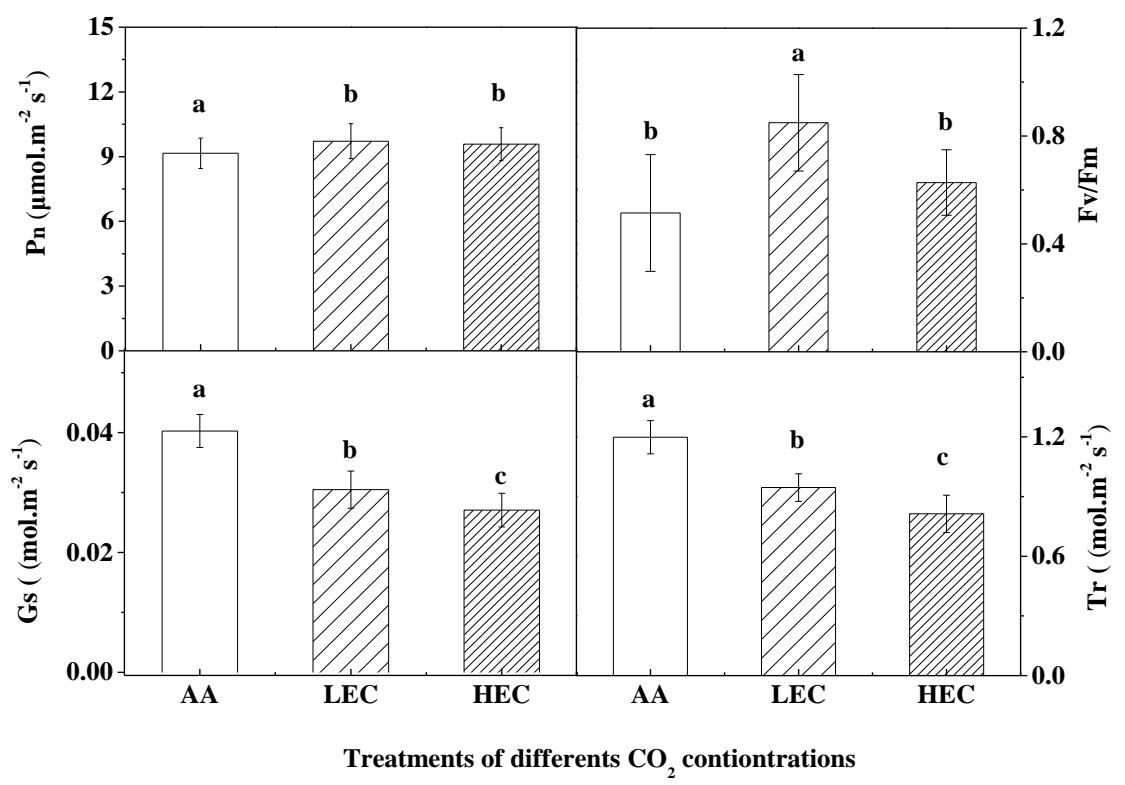

Figure 2. Effects of $\mathrm{CO}_{2}$ treatments on Pn, Fv/Fm, Gs and Tr of rice seedlings. Light-saturated net photosynthesis rate, Pn; Maximum quantum yield of PSII photochemistry, Fv/Fm; Stomatal conductance, Gs; Transpiration rate, $T r .(n=9)$

\section{Effects of elevated $\mathrm{CO}_{2}$ on endogenous hormones contents}

Compare to control, ZT, GA 3 and JA contents were increased significantly $(\mathrm{p}<0.05)$ under LEC and HEC, but IAA content increased significantly $(\mathrm{p}<0.05)$ only under LEC. The maximum value of ZT, IAA and $\mathrm{GA}_{3}$ contents were under LEC. There are no significant different of SA content under every treatment. Compared with AA, ABA content decreased (about 36.3\%) significantly ( $\mathrm{p}<0.05)$ under HEC (Fig. 3).

\section{Effects of elevated $\mathrm{CO}_{2}$ on ratio of endogenous hormones}

IAA/ABA, GA $3 / \mathrm{ABA}, \mathrm{ZT} / \mathrm{ABA}, \mathrm{JA} / \mathrm{ABA}$ and JA/SA all increased under elevated $\mathrm{CO}_{2}$, compared to control. The maximum value of IAA/ABA and $\mathrm{GA}_{3} / \mathrm{ABA}$ were under LEC, while the maximum value of ZT/ABA, JA/ABA and JA/SA were under HEC. JA/GA 3 decreased under LEC and increased under HEC, compared with AA (Fig. 4).

\section{Effects of elevated $\mathrm{CO}_{2}$ on organic acids contents}

In leaves of rice seedlings, compared with AA, there were no significant difference of oxalic acid, citric acid, tartaric acid and acetic acid contents under LEC, but contents of malic acid, lactic acid, fumaric acid and succinic acid significantly decreased $(\mathrm{P}<0.05)$ by $20.1 \%, 28.9 \%, 24.7 \%$ and $37.5 \%$, respectively. Under HEC, contents of oxalic acid, tartaric acid, acetic acid, malic acid, lactic acid, fumaric acid and succinic acid significantly decreased $(\mathrm{P}<0.05)$ by $0.9 \%, 22.2 \%, 32.0 \%, 25.0 \%, 33.5 \%, 33.2 \%$ and $58.5 \%$, respectively, but contents of citric acid showed no significant difference with AA (Fig. 5). 


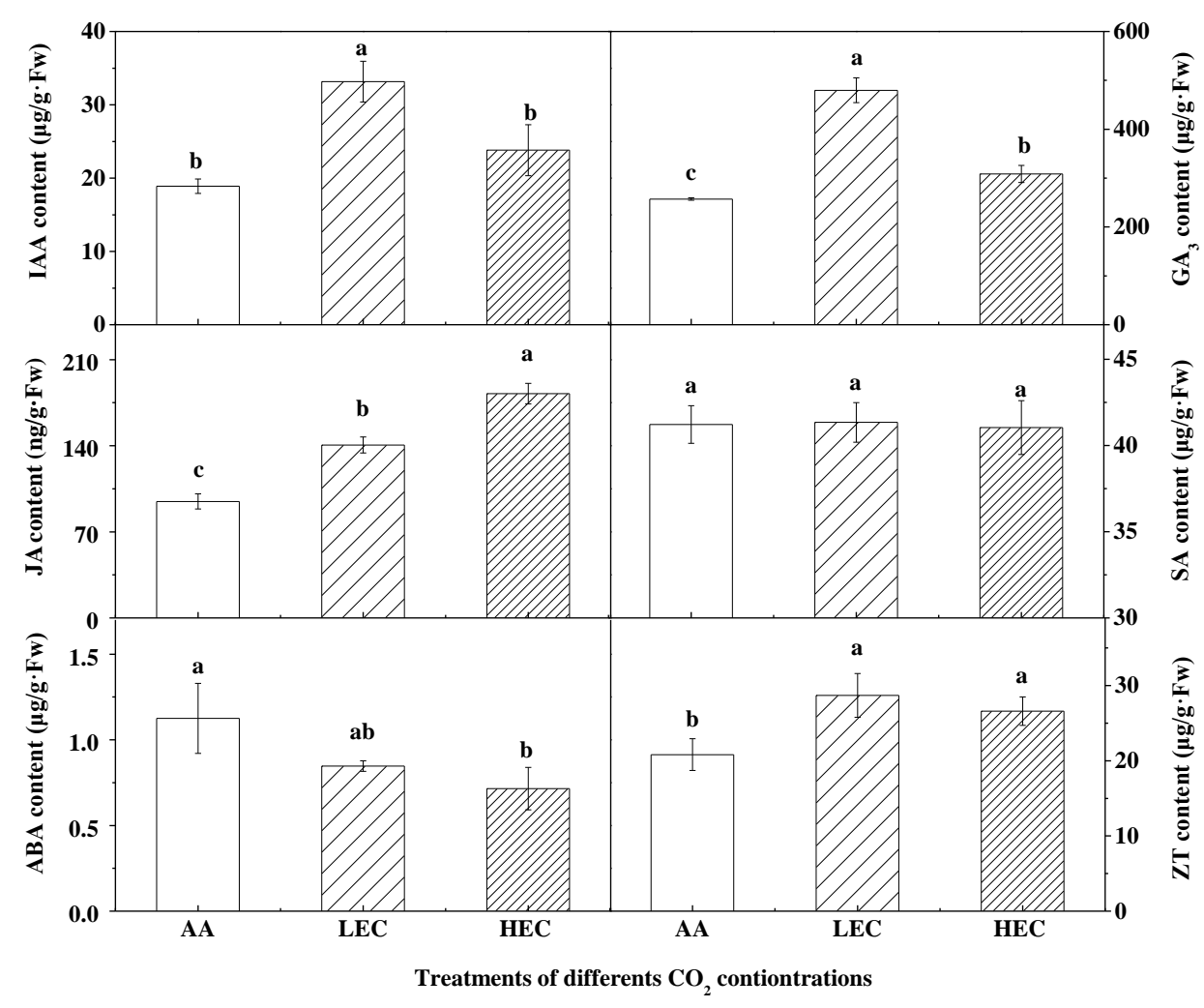

Figure 3. Effects of $\mathrm{CO}_{2}$ treatments on the contents of endogenous hormones in leaves of rice seedlings. $(n=9)$

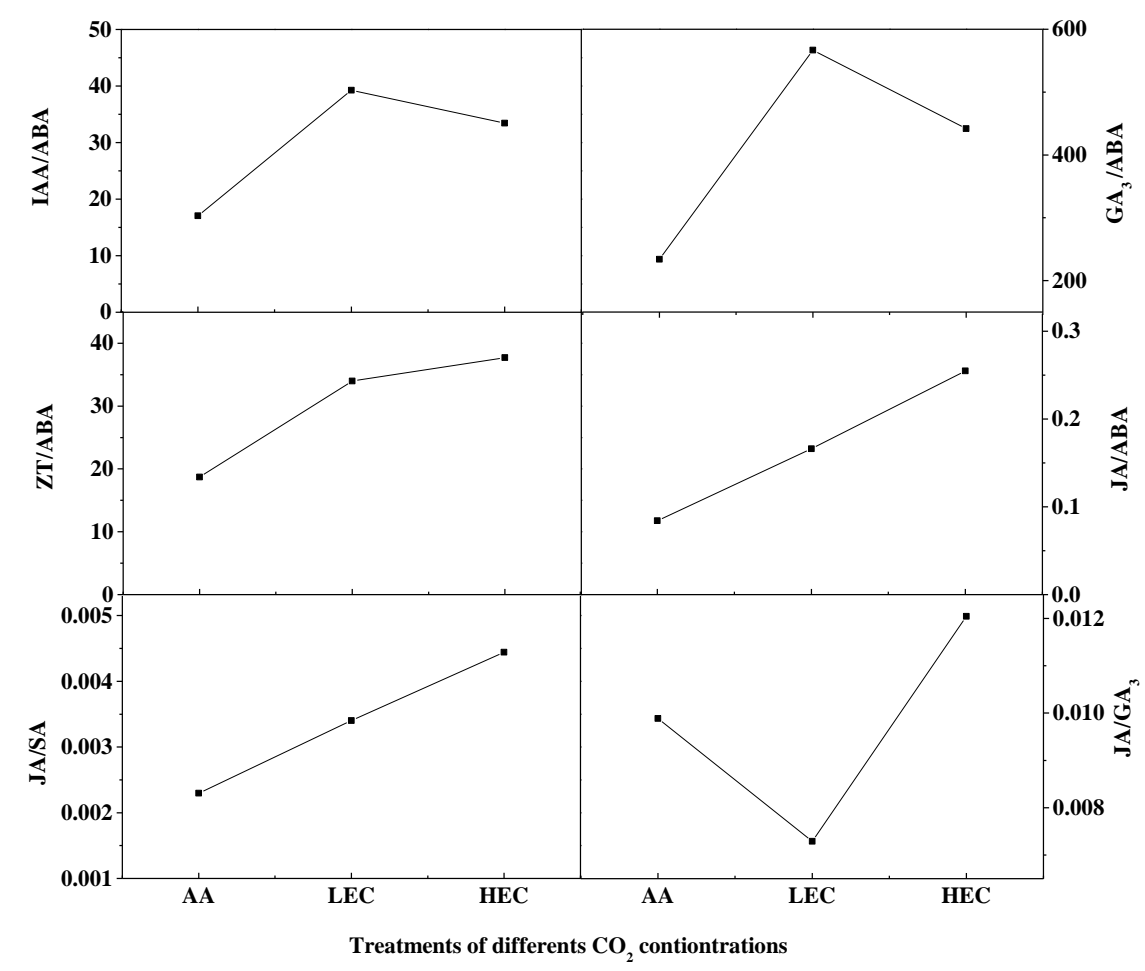

Figure 4. Effects of $\mathrm{CO}_{2}$ treatments on endogenous hormones ratios in leaves of rice seedlings. $(n=9)$ 


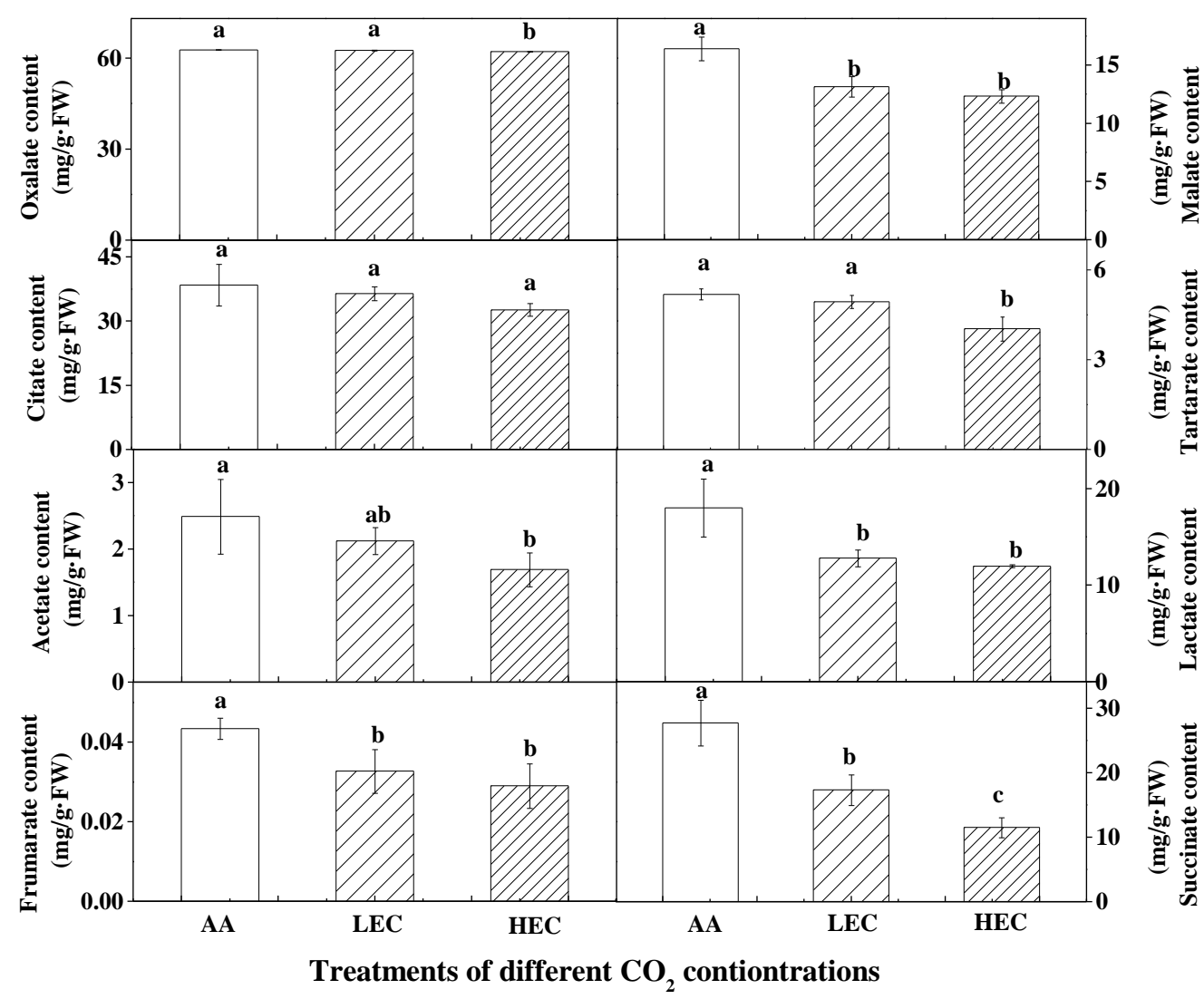

Figure 5. Effects of $\mathrm{CO}_{2}$ treatments on the contents of organic acids in leaves of rice seedlings.

$$
(n=9)
$$

\section{Discussion}

\section{Growth parameters of rice seedlings under elevated $\mathrm{CO}_{2}$}

Plant growth parameters are the most intuitive measurement indexes to reflect the external characteristics of plants. High concentration of $\mathrm{CO}_{2}$ can promote the growth of root and shoot of plant seedlings, thicken leaves, increase crop yield, water use efficiency and biomass (Kimball et al., 1995; Ainsworth, 2008). This study showed that compared with the control, plant height, root length, fresh weight and dry weight of rice seedlings under LEC and HEC were significantly $(\mathrm{p}<0.05)$ increased, which was consistent with the previous research results (Cure and Acock, 1986). This may be because in high $\mathrm{CO}_{2}$ environment, the growth of rice roots is promoted to varying degrees, which can increase the contact area with nutrients, resulting in a significant increase in water and nutrients absorbed, and speed up the transport of water and inorganic salts from underground parts to aboveground parts, thus increasing plant height, root length, fresh weight and dry weight (Rogers et al., 1996).

\section{Stomatal conductance and photosynthesis changes under elevated $\mathrm{CO}_{2}$}

It has been reported that high $\mathrm{CO}_{2}$ can stimulate $\mathrm{Pn}$ in $\mathrm{C}_{3}$ plants (Panigrahi et al., 2016; Lahive et al., 2017). We have also reported elevated $\mathrm{CO}_{2}$ increased $\mathrm{Pn}$ and $\mathrm{Fv} / \mathrm{Fm}$ of $Q$. mongolica leaves generally in two growing seasons, but decreased Gs and $\mathrm{Tr}$ slightly (Wang et al., 2019). However, the short-term $\mathrm{CO}_{2}$-sensing mechanism in guard 
cells to elevated $\mathrm{CO}_{2}$ is still unknown. In this study, $\mathrm{P}_{\mathrm{n}}$ was significantly $(\mathrm{p}<0.05)$ increased under LEC and HEC, and the maximum difference (about 19.1\%) was recorded under LEC, while Fv/Fm also only significantly $(\mathrm{p}<0.05)$ increased under LEC, but not HEC, compared with AA. That means the light reaction of photosynthesis was not promoted more under high $\mathrm{CO}_{2}$ concentration. Elevated $\mathrm{CO}_{2}$ decreased Gs and $\mathrm{Tr}$ significantly $(\mathrm{p}<0.05)$, and the values were lower under HEC than under LEC. That means high $\mathrm{CO}_{2}$ contentions can cause the partly closure of stomata of rice leaves.

\section{Endogenous hormones contents change under elevated $\mathrm{CO}_{2}$}

Environmental signals can modulate plant responses to the changed environments through changes in hormone concentrations and ratios. Endogenous hormones of plant are trace signaling molecules involved in plant metabolism, they can also regulate the whole process of plant growth and development, including the stomatal conductance. In this study, ZT, $\mathrm{GA}_{3}$ and JA contents were all increased significantly $(\mathrm{p}<0.05)$ under elevated $\mathrm{CO}_{2}$, IAA content also increased significantly $(\mathrm{p}<0.05)$, but only under LEC. ABA content decreased (about 36.3\%) significantly $(\mathrm{p}<0.05)$ under HEC. There is no significant difference of SA contents under every treatment.

We have studied, elevated $\mathrm{CO}_{2}$ increased IAA, GA 3 contents, but decreased ABA content ( $\mathrm{Li}$ et al., 2011). IAA is the predominant auxin in most plants, with higher levels in young growing tissues (Bartel, 1997). It has also been reported that IAA content was elevated 56.6\% in leaves of tomato seedlings when the $\mathrm{CO}_{2}$ concentration changed from 350 to $800 \mu \mathrm{mol} / \mathrm{mol}$ (Wang et al., 2009). Since $P_{n}$ and Fv/Fm were increased under the elevated $\mathrm{CO}_{2}$ in our study. Photosynthetic products, such as glucose can induce IAA synthesis pathways in Arabidopsis thaliana through sugar signals (Sairanen et al., 2012). $\mathrm{GA}_{3}$ can also regulate plant growth through integrating multiple signals, and $\mathrm{GA}_{3}$ in leaves can also be increased under elevated $\mathrm{CO}_{2}$ (Teng et al., 2006). In our study, IAA and $\mathrm{GA}_{3}$ contents were all increased under LEC compared with control, but decreased under HEC compared with LEC. That may be resulted in the unchanged Pn between LEC and HEC in rice leaves. Moreover, Fv/Fm even showed no significant change between AC and HEC. Tazoe and Santrucek (2015) reported that stomatal closure induced by elevated $\mathrm{CO}_{2}$ might be mediated by $\mathrm{ABA}$ levels, in our study, high $\mathrm{CO}_{2}$ contentions caused the partly closure of stomata of rice leaves, but ABA content decreased (about $36.3 \%)$ significantly $(\mathrm{p}<0.05)$ under HEC. That showed $\mathrm{CO}_{2}$-mediated stomatal closure does not require ABA, which are the same with some researches (Koornneef et al., 1982; Léon-Kloosterziel et al., 1996). In addition, the elevated $\mathrm{CO}_{2}$ can increase Pn and promote the accumulation of sugars, that maybe make the negative regulation of ABA signaling pathways (Tsai and Gazzarrini, 2014).

JA and SA can participate in the regulation of diverse processes in plants, including growth, photosynthesis and reproductive development (Tariq et al., 2010; Claus, 2015). The partly stomatal closure regulated by JA has been found in some kinds of plants, such as vicia faba and barley (Tsonev et al., 1998; Liu et al., 2007). In this experiment, JA contents increased, but Gs and Tr decreased significantly under LEC and HEC, compared with AA. Maybe, the movements of stoma connected with JA in some degree, but not ABA. Some study has showed that the increasing levels of SA can increase in the growth of the plants (Tariq et al., 2010). The SA-enhanced growth of the plants might be associated with the regulatory effects of SA on cell growth and division (ElTayeb, 2005). Moreover, SA inhibits the breakdown of ribulose-1,5-bisphosphate carboxylase/oxygenase, rubisco, in association with the changes in net photosynthetic 
rate, and content of sugars (Chandra and Bhatt, 1998). But other study's results showed that SA induced growth reduction (Manthe et al., 1992). In our study, there were no significant change of SA contents showed, even though, Pn had increased significantly under elevated $\mathrm{CO}_{2}$, compared with control.

Cytokinins regulate the synthesis of pigments and structural proteins necessary for the formation of the chloroplast thylakoid system and the photosynthetic system, also act as respiration stabilizers, and as a kind of endogenous cytokines, ZT can promote effects of cell division, budding and lateral shoot formation, enhancement of metabolic sinks, as well as inhibition of apical dominance and root development (Kamínek, 2015). In our study, Pn and ZT all increased significantly $(\mathrm{p}<0.05)$ under EC, and Fv/Fm increased under LEC. It is the same with the research have showed the increasing photosynthetic activity, the leaf area and the quantum efficiency of the PS II photochemistry induced by cytokinins (Moura et al., 2017). While, the increase in transpiration rate $(\mathrm{E})$ or stomatal opening by cytokinins has been reported in leaves of some plant species (Pospíšilová and Dodd, 2005), but in our study, Gs was decrease under EC, that maybe resulted in the different species of plants.

\section{Endogenous hormones Ratios changes under elevated $\mathrm{CO}_{2}$}

Plant growth regulators can be used highly flexibly for the "fine-tuning" of crop plants under largely uncontrollable and unpredictable environmental conditions. "True" plant growth regulators interfere directly with the plant's hormonal status. Synergistic or antagonistic interactions among the different hormone groups add to the complexity of the hormonal system in higher plants (Wilhelm, 2015). Usually, IAA, ZT and $\mathrm{GA}_{3}$ are growth-promoting hormones, and $\mathrm{ABA}$ is growth-inhibiting hormone. In our study, IAA/ABA, GA $3 / \mathrm{ABA}$ and $\mathrm{ZT} / \mathrm{ABA}$ were all increased by the elevated $\mathrm{CO}_{2}$, indicated the promoting effects of photosynthesis and growth, that consistent with the results of our previous studies ( $\mathrm{Li}$ et al., 2011). We also find IAA/ABA and GA3/ABA were higher under LEC than HEC, that maybe result in the unchanged Pn between LEC and HEC.

JA is involved in cross-talks (links between activities of various hormones) with ABA, SA and GA (Claus, 2015). In our study, the increased JA/ABA ratio under EC maybe result in the increased Pn and decreased Gs, the unchanged SA content may result in the increase of JA/SA ratio under EC. Researches showed GA-mediated growth, accompanied by weakening of JA-mediated growth inhibition and defense responses. We can find that JA/GA decreased under LEC but increased under HEC, which perhaps because the elevated Pn under LEC, and the severe closure of stomata under HEC.

\section{Organic acids contents changes under elevated $\mathrm{CO}_{2}$}

Organic acids are directly or indirectly involved in other metabolic processes, including carbon and nitrogen metabolism, regulating cytoplasmic $\mathrm{pH}$ and osmotic potential, and balancing the charge of excess absorption of cations (López-Bucio et al., 2000; Igamberdiev, 2018). Due to the central role of organic acids in cell metabolism, their synthesis and concentration are strictly controlled. In the cytoplasm, the concentration of organic acids is relatively stable. But in vacuoles, organic acid concentrations often vary with the environment in response to nutrient availability and metabolic activity (Gerhardt et al., 1987). In our study, the contents of organic acids decreased in leaves of rice under EC. 
Some organic acids (citric acid, succinic acid, fumaric acid, malic acid) are present in all cells and are intermediates in the TCA cycle. In our result, the content of citric acid in leaves of rice seedlings decreased compared with AA, the difference is not significant. The increases of $\mathrm{CO}_{2}$ concentrations promote plants photosynthesis, while chloroplast is the place of photosynthesis. The metabolism of organic acids in plants is related to IDH (isocitrate dehydrogenase, IDH), and the increase of chloroplast activity may lead to the increase of NAHP-IDH distribution, thus promoting the decomposition of citric acid (Hodges et al., 2003; Lemaitre et al., 2007). In addition, citric acid can be secreted from the cytosol to the rhizosphere, preventing excess citric acid from accumulating in vacuoles (Langlade, 2002).

This study showed that succinic acid contents in leaves of rice seedlings decreased under HEC. Succinic acid is produced by SSA (succinic hemialdehyde, SSA) following the action of SSADH (succinate hemialdehyde dehydrogenase, SSADH), a key enzyme in the GABA ( $\gamma$-aminobutyric acid, GABA) metabolic pathway involved in plant defense against environmental stress (Michaeli et al., 2011; Podlešáková et al., 2018). However, the increase of $\mathrm{CO}_{2}$ concentration promotes the growth and development of plants, so SSADH perhaps is kept at a low level, that may result in the decrease of succinic acid synthesis.

Studies have shown that fumarate appears to behave as both a temporary carbon sink for photosynthate similar to starch (Pracharoenwattana et al., 2010). In carrot cells growing on malate as the carbon source, it was discovered that the malate was first converted into fumarate by a fumarase secreted from the cells and then fumarate was taken up and used for growth (Kim and Lee, 2002). In this study, the contents of fumaric acids in leaves decreased significantly under EC, possibly because fumaric acids acted as a temporary carbon sink of photosynthetic product for plant growth, which result the according decrease of fumaric acid contents under EC.

Malic acid, as an important intermediate, is involved in a series of physiological mechanisms in plants (Fernie and Martinoia, 2009; Santelia and Lawson, 2016). Malic acid also plays an important role in the opening and closing of leaf stomata (Raschke, 2003; Lee et al., 2008). In common, malic acid can decrease the stomatal aperture. In this study, malic acid contents of rice seedlings decreased under EC, which may be related to the change of stomata. In another, the decrease of malic acid contents perhaps because the more malic enzymes in chloroplasts of plants, which can catalyze malic acid in cells to produce $\mathrm{CO}_{2}$ through decarboxylation to provide NADPH for $\mathrm{C} 3$ cycle, so as to improve the photosynthetic efficiency of plants (Rangel et al., 2010).

The metabolism of oxalic acid may be related to the photorespiration glycolic acid pathway and the metabolism of ascorbic acid, isocitrate and oxaloacetic acid (Franceschi, 1987; Horner et al., 2000). It is generally believed that leaves are important sites for the synthesis of oxalic acid (Wagner and Loewus, 1973). Studies have shown that oxalic acids synthesis is related to photorespiration and inhibition of photorespiration can block further oxalic acid accumulation (Fujii, 1994). In this study, oxalic acid content decreased significantly under $\mathrm{HEC}$, possibly because the high $\mathrm{CO}_{2}$ inhibited the photorespiration of rice. The accumulation of lactic acid in mature root tissues and the secretion of protons from cytosol to rhizosphere in hypoxic environment not only induced the changes of metabolism and $\mathrm{pH}$ value of rhizosphere, but also acted as the role of acidification and detoxification and preventing the accumulation of excess lactic acid in vacuole (Xia and Roberts, 1994; Langlade, 2002); glycolic acid oxidation pathway is a special glycolytic pathway in rice root system. Under the condition of 
insufficient oxygen supply in rice root, part of acetyl-CoA in root does not enter TCA cycle, but forms acetic acid. Acetic acid is catalyzed by glycolate oxidase to form glycolic acid, and then oxalic acid and formic acid are formed. Meanwhile, reducing substances in the root are oxidized to ensure the physiological function of the root. In our study, there was no low $\mathrm{O}_{2}$ environment, so the lactic acid and acetic acid contents decreased significantly under EC respectively, which may be an adaptation to the $\mathrm{CO}_{2}$ environment. Tartaric acid can detoxify, promote the growth of plants under environmental stress (Chen et al., 2017; Riaz et al., 2018). However, the increase of atmospheric $\mathrm{CO}_{2}$ concentration itself can promote the plant growth, it does not need too much tartaric acid to assist the growth and content of tartaric acid decreased significantly under HEC.

\section{Conclusions}

In the present study, rice seedlings leaves were used to study the changes of photosynthesis, stomatal conductance, endogenous hormones and organic acids contents under elevated $\mathrm{CO}_{2}$. The main results show: Under EC, $\mathrm{P}_{\mathrm{n}}$ and $\mathrm{Fv} / \mathrm{Fm}$ were increased, but Gs and $\operatorname{Tr}$ were decreased significantly $(\mathrm{p}<0.05)$, the partly closure of stomata in rice leaves were induced. IAA, $\mathrm{ZT}$ and $\mathrm{GA}_{3}$ contents were all increased significantly $(\mathrm{p}<0.05)$ under EC, which resulted in the increased Pn. ABA content decreased under HEC, but JA content increased significantly $(\mathrm{p}<0.05)$ under EC, Maybe, the movements of stoma connected with JA in some degree, but not ABA. There are no significant changes of SA contents under EC. In our study, IAA/ABA, GA $3 / A B A$ and ZT/ABA were all increased under $\mathrm{EC}$, indicated the promoting effects of photosynthesis and growth. The increased JA/ABA under EC maybe result in the increased $\mathrm{Pn}$ and decreased Gs. JA/SA increased under EC, and JA/GA decreased under LEC but increased under HEC, which perhaps because the elevated Pn under LEC, and the severe closure of stomata under HEC. The contents of oxalic acid, tartaric acid, acetic acid, malic acid, lactic acid, fumaric acid and succinic acid significantly decreased $(\mathrm{P}<0.05)$ in leaves of rice seedlings under HEC. The variation of organic acids may be a mechanism of plant response to high $\mathrm{CO}_{2}$ environment. The contents of organic acids in the TCA cycle decreased, such as malic acid and fumaric acid, indicating that the TCA cycle rate slowed down. And the organic acids, those with detoxifying effects, such as tartaric acid and oxalic acid significantly decreased $(\mathrm{P}<0.05)$ under HEC. In the future study, the intrinsic molecular mechanism changes of endogenous hormones and organic acids regulation should be concerned. Studies on its metabolome and transcriptome are ongoing.

Acknowledgements. This work was founded by the National Natural Science Foundation of China (31600314), the Department of Education of Liaoning province Foundation (LZD201901, LZD202004), Innovation training program for college students (202106039).

\section{REFERENCES}

[1] Ainsworth, E. A. (2008): Rice production in a change climate: a meta-analysis of responses to elevated carbon dioxide and elevated ozone concentration. - Global Change Biology 14(7): 1642-1650.

[2] Bartel, B. (1997): Auxin biosynthesis. - Annual Review of Plant Biology 48: 51-66. 
[3] Chandra, A., Bhatt, R. K. (1998): Biochemical and physiological response to salicylic acid in relation to the systemic acquired resistance. - Photosynthetica 35: 255-258.

[4] Chen, Y. T., Wang, Y., Yeh, K. C. (2017): Role of root exudates in metal acquisition and tolerance. - Current Opinion in Plant Biology 39: 66-72.

[5] Claus, W. (2015): How Jasmonates Earned their Laurels: Past and Present. - Journal of Plant Growth Regulation 34: 761-794.

[6] Cure, J. D., Acock, B. (1986): Crop responses to carbon dioxide doubling: a literature survey. - Agricultural and Forest Meteorology 38(1-3): 127-145.

[7] Dakora, F. D., Phillips, D. A. (2002): Root exudates as mediators of mineral acquisition in low-nutrient environments. - Plant and Soil 245(1): 35-47.

[8] El-Tayeb, M. A. (2005): Response of barley grains to the interactive e.ect of salinity and salicylic acid. - Plant Growth Regulation 45: 215-224.

[9] Fernie, A. R., Martinoia, E. (2009): Malate. Jack of all trades or master of a few? Phytochemistry 70(7): 828-832.

[10] Franceschi, V. R. (1987): Oxalic acid metabolism and calcium oxalate formation in Lemna minor L. - Plant Cell and Environment 10: 397-406.

[11] Fu, H., Yu, H., Li, T., Zhang, X. (2018): Influence of cadmium stress on root exudates of high cadmium accumulating rice line (Oryza sativa L.). - Ecotoxicology and Environmental Safety 150: 168-175.

[12] Fujii, N., Watanabe, M., Watanabe, Y. (1994): Relationship between oxalate synthesis and glycolate cycle in spinach. - Journal of the Japanese Society for Horticultural Science 62(4): 789-794.

[13] Gehring, C. A., Irving, H. R., McConchie, R., Parish, R. W. (1997): Jasmonates induce intr- acelluar alkaliniza ton and closure of Paphiopedilum guard cells. - Annals of Botany 80: 485-489.

[14] Gerhardt, R., Stitt, M., Heldt, H. W. (1987): Subcellular metabolite levels in spinach leaves. - Plant Physiology 83: 399-407.

[15] Guo, H. G., Wang, S. F., Ge, F. (2017): Effect of elevated $\mathrm{CO}_{2}$ and $\mathrm{O}_{3}$ on phytohormonemediated plant resistance to vector insects and insect-borne plant viruses. - Science China Life Sciences 60: 816-825.

[16] Herde, O., Pena-cortes, H., Willmitzer, L., Fisahn, J. (1997): Stoamtal responses to jasmonic acid, linolenic acid and abscisic acid in wild-type and ABA-deficient tomato plants. - Plant Cell and Environment 20(1): 136-141.

[17] Hoagland, D. R., Arnon, D. I. (1950): The water-culture method for growing plants without soil. - California Agriculture 347: 1-32.

[18] Hodges, M., Flesch, V., Gálvez, S., Bismuth, E. (2003): Higher plant NADP ${ }^{+}$-dependent isocitrate dehydrogenases, ammonium assimilation and NADPH production. - Plant Physiology and Biochemistry 41(6-7): 577-585.

[19] Horner, H. T., Kaush, A. P., Wagner, B. L. (2000): Ascorbic acid: a precursor of oxalate in crystal idioblasts of Yucca torreyi in liquid root culture. - International Journal of Plant Sciences 161(1): 861-868.

[20] Hou, S. J., Zhu, J., Ding, M. Y., Lv, G. H. (2008): Simultaneous determination of gibberellic acid, indole-3-acetic acid and abscisic acid in wheat extracts by solid-phase extraction and liquid chromatography-electrospray tandem mass spectrometry. - Talanta 76: 798-802.

[21] Igamberdiev, A. U., Bykova, N. V. (2018): Role of organic acids in the integration of cellular redox metabolism and mediation of redox signaling in photosynthetic tissues of higher plants. - Free Radical Biology and Medicine 122: 74-85.

[22] IPCC Working Group I. Climate Change (2013): The Physical Science Basis. http://www.climate2013.org/spm.

[23] Javed, M. T., Akram, M. S., Tanwir, K., Javed, C. H., Ali, Q., Stoltz, E., Lindberg, S. (2017): Cadmium spiked soil modulates root organic acids exudation and ionic contents 
of two differentially Cd tolerant maize (Zea mays L.) cultivars. - Ecotoxicology and Environmental Safety 141: 216-225.

[24] Jensen, E., Junttila, O. (1982): Indolyl-3-acetic acid from shoots of Salix pentandra. Plant Physiology 56: 241-244.

[25] Kamínek, M. (2015): Tracking the Story of Cytokinin Research. - Journal of Plant Growth Regulation 34(4): 723-739.

[26] Kim, S., Lee, W. (2002): Participation of extracellular fumarase in the utilization of malate in cultured carrot cells. - Plant Cell Reports 20: 1087-1092.

[27] Kimball, B. A., Pinter, P., Garcia, R. L., LaMorte, R. L., Wall, G. W., Hunsaker, D., Wechsung, G., Wechsung, F., Kartschall, T. (1995): Productivity and water use of wheat under free-air $\mathrm{CO}_{2}$ enrichment. - Global change biology 1(6): 429-442.

[28] Koornneef, M., Jorna, M. L., Brinkhorst-van der Swan, D. L. C., Karssen, C. M. (1982): The isolation of abscisic acid (ABA) deficient mutants by selection of induced revertants in non-germinating gibberellin sensitive lines of Arabidopsis thaliana (L.). - Theoretical and Applied Genetics 61: 385-393.

[29] Lahive, F., Hadley, P., Daymond, A. J. (2017): The impact of elevated $\mathrm{CO}_{2}$ and water deficit stress on growth and photosynthesis of juvenile cacao (Theobroma cacao L.). Photosynthetica 56: 911-920.

[30] Langlade, N. B. (2002): A physiolocal and development of cluster roots in white lupin (Lupinusalbus L.). - The University of Neuchatel, Neuchtel, Switzerland.

[31] Lee, M., Choi, Y., Burla, B., Kim, Y. Y., Jeon, B., Maeshima, M., Yoo, J. Y., Martionoia, E., Lee, Y. (2008): The ABC transporter AtABCB14 is a malate importer and modulates stomatal response to $\mathrm{CO}_{2}$. - Nature Cell Biology 10: 1217-1223.

[32] Lemaitre, T., Urbanczyk-Wochniak, E., Flesch, V., Bismuth, E., Fernie, A. R., Hodges, M. (2007): NAD-Dependent Isocitrate Dehydrogenase Mutants of Arabidopsis Suggest the Enzyme Is Not Limiting for Nitrogen Assimilation. - Plant Physiology 144(3): 15461558.

[33] Léon-Kloosterziel, K. M., Gil, M. A., Ruijs, G. J., Jacobsen, S. E., Olszewski, N. E., Schwartz, S. H., Zeevaart, J. A. D., Koornneef, M. (1996): Isolation and characterization of abscisic acid-deficient Arabidopsis mutants at two new loci. - Plant Journal 10: 655661.

[34] Li, X. M., Zhang, L. H., Li, Y. Y., Ma, L. J., Chen, Q., Wang, L. L., He, X. Y. (2011): Effects of elevated carbon dioxide and/or ozone on endogenous plant hormones in the leaves of Ginkgo biloba. - Acta Physiologiae Planturam 33: 129-136.

[35] Liu, X., Li, Y., Meng, F. X., Zhang, S. Q. (2007): $\mathrm{H}^{+}$involving signal transduction in regulation of Vicia faba L. stomatal movement by jasmonic acid. - Plant Physiology Communications 43(2): 245-249.

[36] Lodi, S., Rossin, G. (1995): Determination of some organic acids in sugar factory products. - Journal of Chromatography A 706: 375-383.

[37] López-Bucio, J., Nieto-Jacobo, M. F., Ramírez-Rodríguez, V., Herrera-Estrella, L. (2000): Organic acid metabolism in plants: from adaptive physiology to transgenic varieties for cultivation in extreme soils. - Plant Science 160(1): 1-13.

[38] Manthe, B., Schulz, M., Schnabl, H. (1992): Effects of salicylic acid on growth and stomatal movements of Vicia faba L.: Evidence for salicylic acid metabolization. Journal of Chemical Ecology 18(9): 1525-1539.

[39] Marten, I., Lohse, G., Hedrich, R. (1991): Plant growth hormones control voltagedependent activity of anion channels in plasma membrane of guard cells. - Nature 353: 758-762.

[40] McAdam, S. A. M., Brodribb, T. J., Ross, J. J., Jordan, G. J. (2011): Augmentation of abscisic acid (ABA) levels by drought does not induce short-term stomatal sensitivity to $\mathrm{CO}_{2}$ in two divergent conifer species. - Journal of Experimental Botany 62(1): 195-203.

[41] Michaeli, S., Fait, A., Lagor, K., Nunes-Nesi, A., Grillich, N., Yellin, A., Bar, D., Khan, M., Fernie, A. R., Turano, F. J., Fromm, H. (2011): A mitochondrial GABA permease 
connects the GABA shunt and the TCA cycle, and is essential for normal carbon metabolism. - The Plant Journal 67(3): 485-498.

[42] Moura, F. B., Vieira, M. R., SimÕes, A. N., Silva, S. L. F., Medeiros, D. C., Paes, R. A., Oliveira, A. A. S., Nascimento, A. H. C., Júnior, W. S. E. (2017): Participation of cytokinin on gas exchange and antioxidant enzymes activities. - Indian Journal of Plant Physiology 22(1): 16-29.

[43] Panigrahi, S., Pradhan, M. K., Panda, D. K., Panda, S. K., Joship, N. (2016): Diminution of photosynthesis in rice (Oryza sativa L.) seedlings under elevated $\mathrm{CO}_{2}$ concentration and increased temperature. - Photosynthetica 54: 359-366.

[44] Podlešáková, K., Ugena, L., Spíchal, L., Doležal, K., De, D. N. (2018): Phytohormones and polyamines regulate plant stress responses by altering GABA pathway. - New Biotechnology 48: 53-65.

[45] Pospíšilová, J., Dodd, I. C. (2005): Role of plant growth regulators in stomatal limitation to photosynthesis during water stress. - In: Pessarakli, M. (ed.) Handbook of photosynthesis. Marcel Dekker, New York, pp. 811-825.

[46] Pracharoenwattana, I., Zhou, W., Keech, O., Francisco, P. B., Udomchalothorn, T., Tschoep, H., Smith, S. M. (2010): Arabidopsis has a cytosolic fumarase required for the massive allocation of photosynthate into fumaric acid and for rapid plant growth on high nitrogen. - The Plant Journal 62(5): 785-795.

[47] Rangel, A. F., Rao, I. M., Braun, H. P., Horst, W. J. (2010): Aluminum resistance in common bean (Phaseolus vulgaris) involves induction and maintenance of citrate exudation from root apices. - Physiologia Plantarum 138(2): 176-190.

[48] Raschke, K. (2003): Alteration of the slow with the quick anion conductance in whole guard cells effected by external malate. - Planta 217: 651-657.

[49] Riaz, M., Yan, L., Wu, X., Hussain, S., Aziz, O., Jiang, C. (2018): Mechanisms of organic acids and boron induced tolerance of aluminum toxicity: A review. Ecotoxicology and Environmental Safety 165: 25-35.

[50] Rogers, H. H., Prior, S. A., Runion, G. B., Mitchell, R. J. (1996): Root to shoot ratio of crops as influenced by $\mathrm{CO}_{2}$. - Plant and Soil 187(2): 229-248.

[51] Sairanen, I., Novák, O., Pěnčík, A., Ikeda, Y., Jones, B., Sandberg, G., Ljung, K. (2012): Soluble carbohydrates regulate auxin biosynthesis via PIF proteins in Arabidopsis. Plant Cell 24: 4907-4916.

[52] Santelia, D., Lawson, T. (2016): Rethinking Guard Cell Metabolism. - Plant Physiology 172(3): 1371-1392.

[53] Tanaka, Y., Nose, T., Jikumaru, Y., Kamiya, Y. (2013): ABA inhibits entry into stomatal line- age development in Arabidopsis leaves. - Plant Journal 74: 448-457.

[54] Tariq, A. M., Masroor, A., Khan, M. I. M., Naeem, M. (2010): Salicylic Acid acts as Potent Enhancer of Growth, Photosynthesis and Artemisinin Production in Artemisia annua L. - Journal of Crop Science and Biotechnology 13(3): 183-188.

[55] Tazoe, Y., Santrucek, J. (2015): Superimposed behaviour of gm under ABA-induced stomata closing and low $\mathrm{CO}_{2}$. - Plant Cell and Environment 38: 385-387.

[56] Teng, N. J., Wang, J., Chen, T., Wu, X. Q., Wang, Y. H., Lin, J. X. (2006): Elevated $\mathrm{CO}_{2}$ induces physiological, biochemical and structural changes in leaves of Arabidopsis thaliana. - New Phytologist 172(1): 92-103.

[57] Tsai, A. Y., Gazzarrini, S. (2014): Trehalose-6-phosphate and SnRK1 kinases in plant development and signaling: the merging picture. - Frontiers in Plant Science 5: 119.

[58] Tsonev, T. D., Lazova, G. N., Stoinova, Z. G., Popova, L. P. (1998): A possible role for jasmonic acid in adaptation of barley seedlings to salinity stress. - Journal of Plant Growth Regulation 17(3): 153-159.

[59] Wagner, G., Loewus, F. (1973): The biosynthesis of (+)-tartaric acid in Pelargonium crispum. - Plant Physiology 52: 651-654. 
[60] Wang, Y., Du, S. T., Li, L. L., Huang, L. D., Fang, P., Lin, X. Y., Zhang, Y. S., Wang, H. L. (2009): Effect of $\mathrm{CO}_{2}$ Elevation on root growth and its relationship with indole acetic acid and ethylene in tomato seedlings. - Pedosphere 19(5): 570-576.

[61] Wang, L. L., Li, Y. Y., Li, X. M., Ma, L. J., He, X. Y. (2019): Co-ordination of photosynthesis and stomatal responses of Quercus mongolica to elevated $\mathrm{O}_{3}$ and/or $\mathrm{CO}_{2}$. - Applied Ecology and Environmental Research 17(2): 4257-4268.

[62] Wilhelm, R. (2015): Plant Growth Regulators: Backgrounds and Uses in Plant Production. - Journal of Plant Growth Regulation 34: 845-872.

[63] Xia, J. H., Roberts, J. K. M. (1994): Improved cytoplasmic pH regulation, increased lactate efflux, and reduced cytoplasmic lactate levels are biochemical traits expressed in root tips of whole maize seedings acclimated to a low-oxygen environment. - Plant Physiology 105: 651-657.

[64] Zhen, M. Y., Mayandi, S., Walter, J. H., Hideaki, M. (2000): Aluminium tolerance is achieved by exudation of citric acid from roots of soybean (Glycine max). - Physiologia Plantarum 110(1): 72-77. 